\title{
Initial Development of an Electrical Power Generator by using Thermoelectric Generator, Focal Lens and Underground Heat Dissipation System
}

\author{
Syed Zainal Abidin Syed Kamarul Bahrin, Sabarina Jaafar \\ Department of Electrical Power Engineering, Universiti Tenaga Nasional, Malaysia
}

\begin{abstract}
Article Info
Article history:

Received Feb 22, 2018

Revised May 20, 2018

Accepted May 28, 2018

\section{Keyword:}

Convex lens

Fresnel lens

Solar concentrator

Thermoelectric generator

Underground cooling

ABSTRACT

Electrical energy is important in various developments to ensure global stability. However, most electrical energy sources are non-renewable and these sources are expected to be depleted in the near future. In order to solve this problem, research on renewable energy sources are intensified and thermoelectric generator (TEG) is one of the potential solutions. TEG can generate electricity if the there is a temperature difference between the hot end and cold end of its plate and it is widely used in various applications, ranging from high temperature of a steam generator until to the lowest temperature of a human body. The initial development of this work focuses on the electrical power generator design by using focal lens to focus sunlight, a form of renewable energy, on the TEG hot end and also underground heat dissipation system on the cold end to create temperature difference. The initial results showed that the amount of power produced by the system is quite small but reasonable due to the type of TEGs used. However, the heat dissipation system showed a promising development due to its nondependency on external energy to expel heat from the cold side.
\end{abstract}

Copyright $@ 2018$ Institute of Advanced Engineering and Science. All rights reserved.

\section{Corresponding Author:}

Syed Zainal Abidin Syed Kamarul Bahrin,

Department of Electrical Power Engineering,

Universiti Tenaga Nasional,

Jalan IKRAM-UNITEN, 43000 Kajang, Selangor, Malaysia.

Email: SZainal@uniten.edu.my

\section{INTRODUCTION}

\subsection{Overview}

Electrical energy is essential in ensuring progressive development and sustainability of industries, residences and many more. There are two types of energy available to produce electricity; non-renewable and renewable energy. Non-renewable energy is expected to be depleted in time and it is typically obtained from underneath the earth such as coal, natural gas and fossil fuel [1]. Meanwhile, renewable energy is obtained from the sun or astronomical movements such as solar, wind and water [2]. Currently, 78.8 percent of world electricity generations are from non-renewable energy and only 21.2 percent are from renewable energy [3]. Since a large percentage of electricity generations are from non-renewable energy, the world might face disastrous energy crisis in the near future. This crisis can cause global panic and unrest if it is not settled properly and in a timely manner. Therefore, future electricity generations must focus on renewable energy to sustain global energy demands and thermoelectric generator (TEG) is one of the solutions.

\subsection{TEG fundamental concept}

TEG is a solid state device that converts heat or any form of elements that have temperature differences into electrical energy based on the Seebeck effect [4]. TEG is similar to other type of heat-based generators such as steam turbine and gas turbine generators in term of functionality, but this converter is 
more compact and has no moving parts. However, TEG is less efficient [5], even with the latest finding and research [6], [7]. This is mainly due to its high output resistance, which is a common characteristic of a sensor rather than a generator.

In 1821, Thomas Johann Seebeck discovered that a thermal gradient formed between two dissimilar conductors can produce electricity [8]. The temperature gradient in a conducting material results in heat flow, which subsequently causes diffusion of charge carriers. The flow of charge carriers between the hot and cold regions in turn creates a voltage difference. This is the principal operation of a TEG and it can be seen that electrical power can only be produced if there is a temperature different from each side or plate of the TEG. The basic construction and working principle of a TEG is shown in Figure 1.

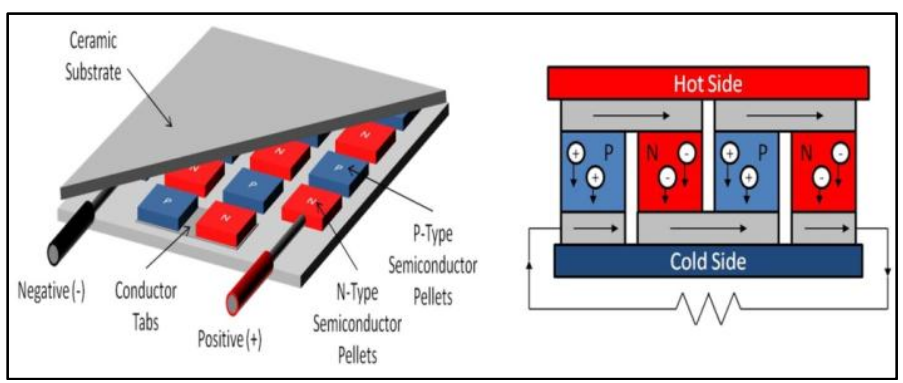

Figure 1. Basic TEG construction and operation

\subsection{TEG implementations and technologies}

TEGs are generally used in power plants to convert waste heat into additional electrical power [9] and also in automobiles [10]-[12]. The latest developments of TEGs have also allowed this particular device to utilize human body heat to power up small devices [13] and heat from heat sink for electronics amplification [14], [15] .TEGs are also used in tandem with solar concentrator [16], [17] such as focal lenses (e.g. convex lens, bi-convex lens, fresnel lens, etc.) and mirrors to concentrate heat from sunlight to the hot end side of the TEGs. Since TEGs can produce electricity from sunlight, the utilization of TEGs with solar concentrator can be categorized as a renewable energy system.

Regardless of the temperature's value at the TEG's hot side, electricity can only be produced if there is a temperature difference between the hot and cold sides. The cold side's temperature will increase as the hot side temperature increases at a given load. Therefore, the cold side has to expel or dissipate the heat to ensure a temperature difference between both sides. The heat is usually expelled or dissipated from the cold side through heat sink which is later cooled off by using fans, water-cooled radiator, ice or ambient temperature. Except for ambient temperature, these cooling methods will cause the TEG operation to be less efficient because these methods require external power to operate (parasitic loss). The ambient temperature is also not effective in expelling heat consistently as presented in [16], which will subsequently reduce the TEG output power due to a lower temperature difference.

Similar to solar photovoltaic technology, TEGs can be arranged in parallel and series to increase the overall terminal voltage and output power. Therefore, most technological advancement in photovoltaic such as boost technology [18] and maximum power point tracking (MPPT) [19], [20] are already applied in TEG for optimized performance.

\subsection{Project initial design and concept}

The initial development of this project is based on a solar concentrator, TEG and underground heat dissipation system design to produce electricity. This particular design is chosen because the energy is based on a renewable energy source that is readily available (sunlight) and the underground relatively constant temperature [21], [22] that require no external power for cooling. The concept of a concentrated sunlight, TEG and underground cooling system is expected to produce more electrical power due to the absence of parasitic loss in the cooling system and the high temperature difference between the TEG hot and cold sides.

For the initial project experimentation, the TEGs are arranged in an array and metal sheet is laid upon the hot side (top side) of the TEGs. The cold side (bottom side) of the TEGs are connected to heat sink and buried underneath a damped soil. Fresnel lens is located above the metal sheet and the distance is determined by the size and type of fresnel lens that will be used. An example of a TEG, metal sheet, heat sink and focal lens (fresnel lens) arrangement is shown in Figure 2. 


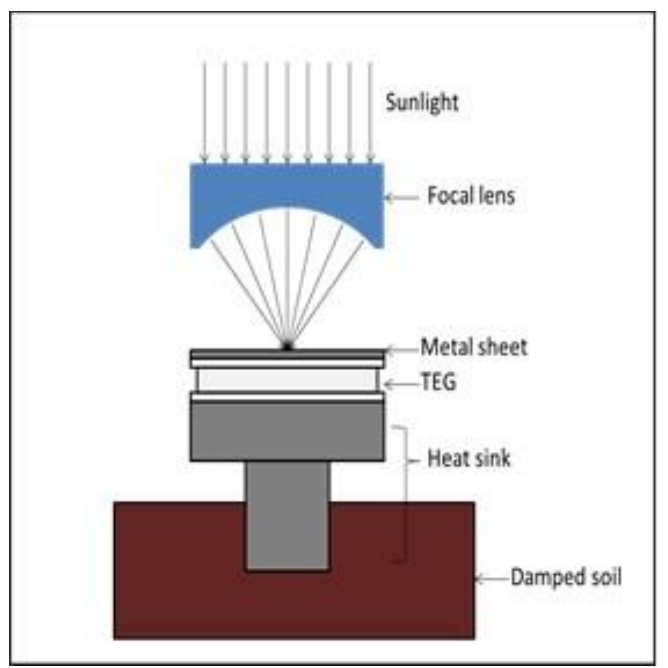

Figure 2. Initial design of the solar-to-electrical power generator

With an appropriate distance, the focal point of the lens will cause the heat from sunlight to increase the temperature of the metal sheet and also the top side of the TEGs. The lens will also cause the metal sheet to be heated all the time regardless of the sun's position. Since the bottom side of the TEGs are connected to the heat sink and damped soil, the temperature is expected to be lower or cooler. The difference in temperature of the top and bottom side will generate voltage and output power if a load is connected to the terminals of the TEGs array. The larger is the temperature difference, the more power the TEGs array can produce.

\section{RESEARCH METHOD}

\subsection{Schematic diagram}

The schematic diagram of the TEGs array is shown in Figure 3. There are eight TEGs connected in parallel to the resistive load with each TEG positive terminal connects to a diode. The parallel connection can reduce the output resistance to produce more current and the diode can prevent current back flow when the voltage generated by each of the TEG is not the same due to non-uniform heat distribution of the metal sheet.

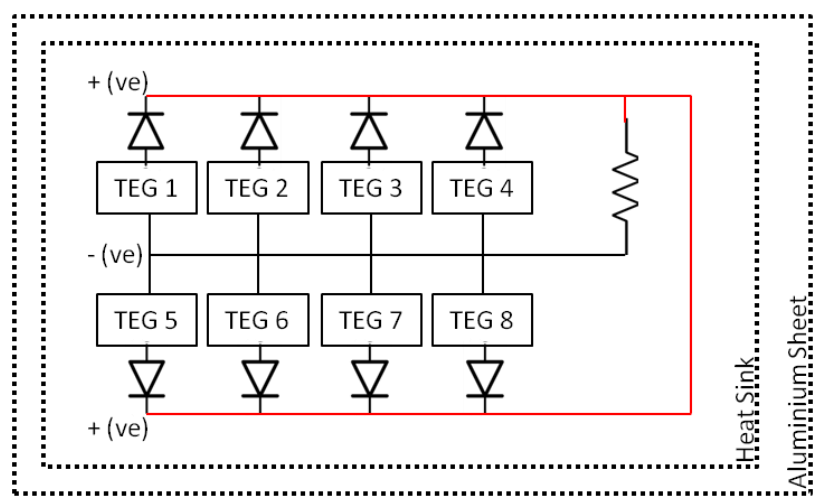

Figure 3. Schematic diagram of the TEGs array. The TEGs are placed in between the aluminium sheet and heat sink

\subsection{Initial prototype}

The initial prototype, which is shown in Figure 4, was built based on the design considerations of the maximum TEG ratings. 


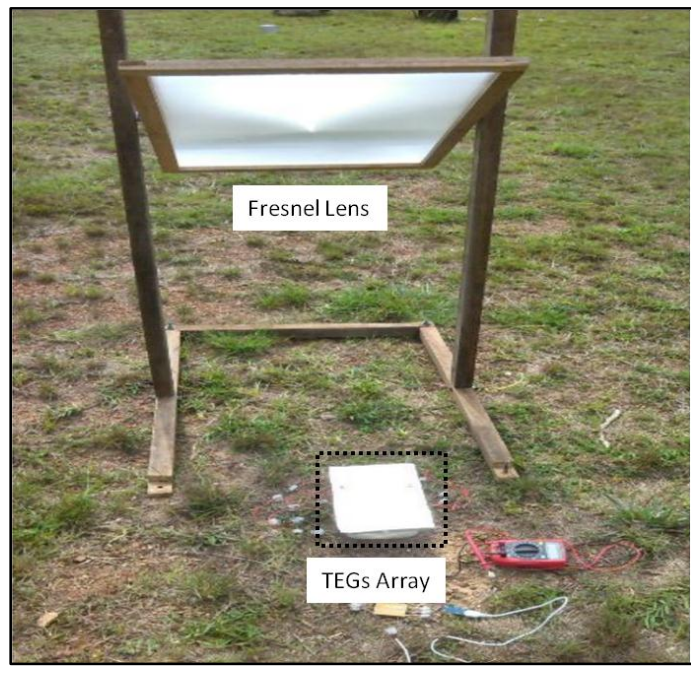

(a)

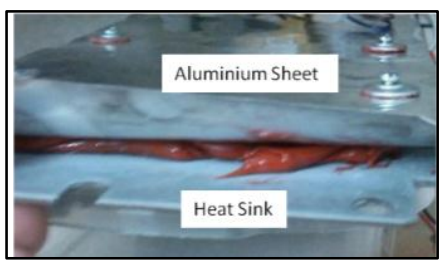

(b)

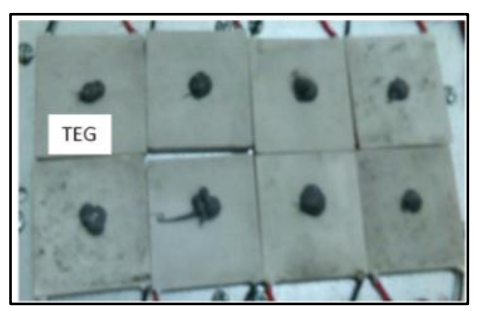

(c)

Figure 4. (a) The overall prototype setup used for experimentations and (b) The tegs array where the (c) Tegs are placed in between the aluminium sheet and heat sink

\subsubsection{TEG}

For the initial development, the type of TEG that was used for the experimentations is based on peltier element due to its low cost [23]. The performance and operating temperature parameters of the peltier (SP1848-27145) are shown in Table 1 and Table 2 respectively.

Table 1. Performance Parameters.

\begin{tabular}{cccc}
\hline $\mathrm{T}_{\min }$ & $\mathrm{T}_{\max }$ & Solder melting point & Compression strength \\
\hline$-27^{\circ} \mathrm{C}$ & $150^{\circ} \mathrm{C}$ & $138^{\circ} \mathrm{C}$ & $1 \mathrm{Mpa}$ \\
\hline
\end{tabular}

Table 2. Operating Temperature Parameters.

\begin{tabular}{ccc}
\hline$\Delta \mathrm{T}\left({ }^{\circ} \mathrm{C}\right)$ & Open Circuit Voltage $(\mathrm{V})$ & Short Circuit Current $(\mathrm{mA})$ \\
\hline 20 & 0.97 & 225 \\
40 & 1.8 & 368 \\
60 & 2.4 & 469 \\
80 & 3.6 & 558 \\
100 & 4.8 & 669 \\
\hline
\end{tabular}

\subsubsection{Fresnel lens}

Fresnel lens was used because it can focus light better than other types of lenses, namely convex lens. Fresnel lens has the same properties as the convex lens as a converging lens but because of its thickness, fresnel lens is able to focus heat better because the lens is less thicker. This indirectly reduces the resistance of the light that penetrates the surface of the lens, thereby reducing refraction of light to other places other than the focal point. For the initial development, Linear Fresnel Lens TV Solar Oven with a dimension of $53.54 \times 83.82 \mathrm{~cm}, 66.04-83.82 \mathrm{~cm}$ focal length and $132^{\circ} \mathrm{C}$ maximum temperature produced was used.

\subsubsection{Diode and resistive load}

The diode's model that was used for the initial development is 1N5822 because it can withstand a large reverse voltage with low voltage drop $(0.525 \mathrm{~V})$. Meanwhile, three $10 \Omega, 10 \mathrm{~W}$ resistors were connected in parallel to produce a resultant resistance of $3.33 \Omega$ for the load.

\subsection{Location and data collection}

The experimentations were performed at an open area, as shown in Figure 4, to obtain optimum sunlight during the day. These experimentations were carried out for seven hours starting from 10 a.m. until 5 p.m. for three different days to ensure consistency, with data taken in an interval time of one hour. During 
experimentations, the fresnel lens's angle was repositioned in according to the sun's position to achieve optimum sunlight concentration.

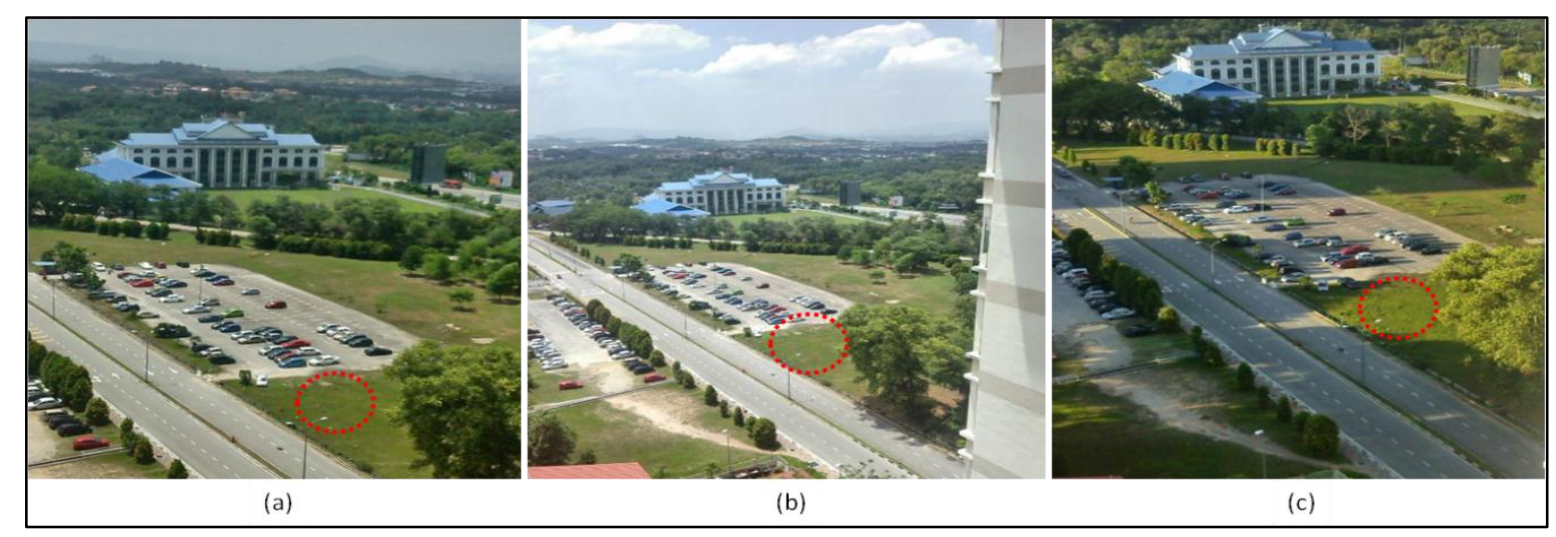

Figure 5. The 3-day experimentations were performed at the specified location (dotted circle) where the location was exposed to direct sunlight in the (a) Morning, (b) Noon and (c) Afternoon

Four data were taken for the 3-day experimentations; voltage across the load $\left(\mathrm{V}_{\mathrm{LOAD}}\right)$, current flowing through the load $\left(\mathrm{I}_{\mathrm{LOAD}}\right)$, temperature at the aluminum sheet or the hot side temperature $\left(\mathrm{T}_{\mathrm{HOT}}\right)$ and temperature at the heat sink or the cold side temperature $\left(\mathrm{T}_{\mathrm{COLD}}\right)$.

\section{RESULTS AND ANALYSIS}

Experimentation results taken for Day 1, Day 2 and Day 3 are shown in Table 3, Table 4 and Table 5 respectively.

Table 3. Result for Day 1

\begin{tabular}{rrrrrrr}
\hline Time & $\mathrm{V}_{\text {LOAD }}(\mathrm{V})$ & $\mathrm{I}_{\text {LOAD }}(\mathrm{A})$ & $\mathrm{P}_{\mathrm{LOAD}}(\mathrm{W})$ & $\mathrm{T}_{\mathrm{HOT}}\left({ }^{\circ} \mathrm{C}\right)$ & $\mathrm{T}_{\mathrm{COLD}}\left({ }^{\circ} \mathrm{C}\right)$ & $\Delta \mathrm{T}\left({ }^{\circ} \mathrm{C}\right)$ \\
\hline 1000 & 0.20 & 0.23 & 0.05 & 38 & 28 & 10 \\
1100 & 0.76 & 1.31 & 1.00 & 55 & 30 & 25 \\
1200 & 3.06 & 2.74 & 8.38 & 103 & 33 & 70 \\
1300 & 3.80 & 3.84 & 14.59 & 128 & 33 & 95 \\
1400 & 3.78 & 3.06 & 11.57 & 111 & 31 & 80 \\
1500 & 1.96 & 2.06 & 4.04 & 73 & 30 & 41 \\
1600 & 1.14 & 1.09 & 1.24 & 50 & 30 & 20 \\
1700 & 0.20 & 0.14 & 0.03 & 38 & 8 \\
\hline
\end{tabular}

Table 4. Result for Day 2

\begin{tabular}{rrrrrrr}
\hline Time & $\mathrm{V}_{\text {LOAD }}(\mathrm{V})$ & $\mathrm{I}_{\text {LOAD }}(\mathrm{A})$ & $\mathrm{P}_{\text {LOAD }}(\mathrm{W})$ & $\mathrm{T}_{\text {HOT }}\left({ }^{\circ} \mathrm{C}\right)$ & $\mathrm{T}_{\mathrm{COLD}}\left({ }^{\circ} \mathrm{C}\right)$ & $\Delta \mathrm{T}\left({ }^{\circ} \mathrm{C}\right)$ \\
\hline 1000 & 0.52 & 0.68 & 0.35 & 43 & 28 & 15 \\
1100 & 1.24 & 1.58 & 1.96 & 60 & 30 & 30 \\
1200 & 3.10 & 2.96 & 9.18 & 107 & 33 & 74 \\
1300 & 1.48 & 1.85 & 2.74 & 66 & 31 & 35 \\
1400 & 3.20 & 2.78 & 8.90 & 103 & 32 & 71 \\
1500 & 1.24 & 1.67 & 2.07 & 64 & 30 & 32 \\
1600 & 1.00 & 1.32 & 1.32 & 35 & 31 & 5 \\
1700 & 0.04 & 0.12 & 0.00 & 36 & 55 \\
\hline
\end{tabular}

Table 5. Result for Day 3

\begin{tabular}{|c|c|c|c|c|c|c|}
\hline Time & $\mathrm{V}_{\mathrm{LOAD}}(\mathrm{V})$ & $\mathrm{I}_{\mathrm{LOAD}}(\mathrm{A})$ & $\mathrm{P}_{\mathrm{LOAD}}(\mathrm{W})$ & $\mathrm{T}_{\mathrm{HOT}}\left({ }^{\circ} \mathrm{C}\right)$ & $\mathrm{T}_{\mathrm{COLD}}\left({ }^{\circ} \mathrm{C}\right)$ & $\Delta \mathrm{T}\left({ }^{\circ} \mathrm{C}\right)$ \\
\hline 1000 & 0.20 & 0.23 & 0.05 & 38 & 28 & 10 \\
\hline 1100 & 0.76 & 1.09 & 0.83 & 50 & 30 & 20 \\
\hline 1200 & 3.16 & 2.74 & 8.66 & 103 & 33 & 70 \\
\hline 1300 & 3.88 & 3.26 & 12.65 & 166 & 31 & 135 \\
\hline 1400 & 3.78 & 3.23 & 12.21 & 115 & 32 & 83 \\
\hline 1500 & 1.96 & 2.12 & 4.16 & 77 & 32 & 45 \\
\hline 1600 & 1.14 & 1.46 & 1.66 & 58 & 30 & 28 \\
\hline 1700 & 0.20 & 0.34 & 0.07 & 41 & 31 & 10 \\
\hline
\end{tabular}




\subsection{Temperature difference/gradient and load power}

The changes in load power and temperature difference of the TEGs array from 10 a.m. until 5.00 p.m. for Day 1, Day 2 and Day 3 are illustrated in Figure 6 and Figure 7 respectively.

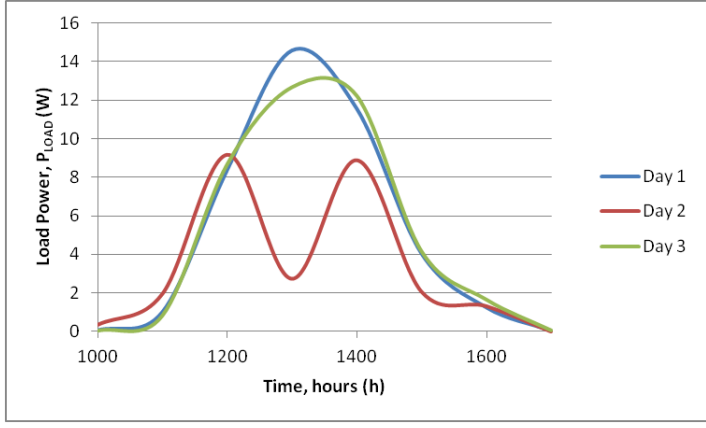

Figure 6. Power produced at the load for Day 1, Day 2 and Day 3

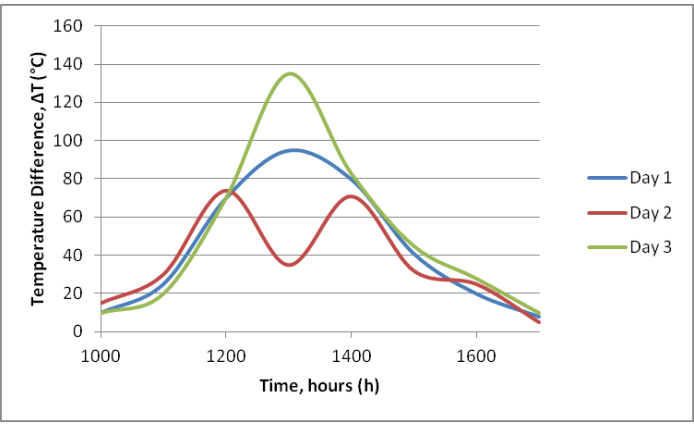

Figure 7. Temperature difference between the tegs array hot and cold sides for Day 1, Day 2 and Day 3

It can be seen that the amount of power produced at the load and the temperature difference between the hot and cold sides have similar pattern, except for Day 2 due to cloud shading (approximately 30 minutes). The pattern indicates that the value increases from morning until early afternoon (maximum) and later decreases as time approaches evening hours. This characteristic is similar to a solar photovoltaic because maximum solar radiation occurs at noon.

It can also be seen that the power produced at the load increases as the temperature difference between the hot and cold sides' increases. This data is in coherent with the basic principle of TEG (higher temperature difference produces more power). However, the maximum temperature difference on Day 3 $\left(135^{\circ} \mathrm{C}\right)$ is higher than Day $2\left(95^{\circ} \mathrm{C}\right)$ and yet produces lesser amount of power $(12.65 \mathrm{~W}$ as compared to $14.59 \mathrm{~W})$. This might be due to some loosen wiring solder or deteriorating TEG modules as the temperature has exceeded the maximum performance parameters.

\subsection{Cold and hot side temperature}

The changes in temperature at the hot and cold side from 10 a.m. until 5.00 p.m. for Day 1, Day 2 and Day 3 is visualised in Figure 8.

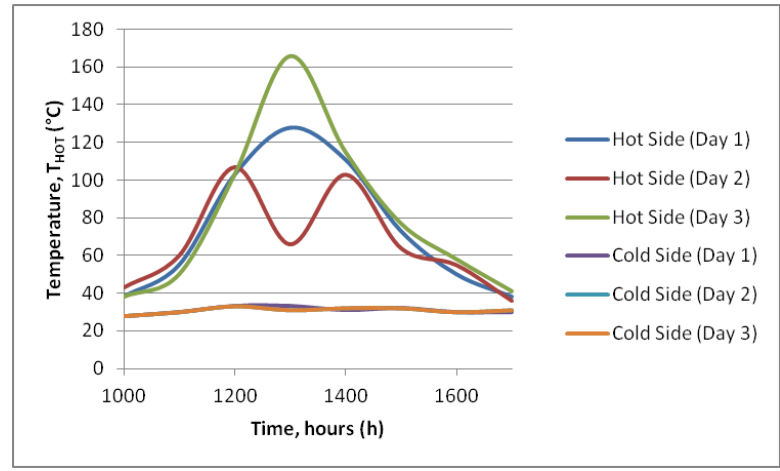

Figure 8. Temperature at the Hot and Cold Side of the TEGs Array for Day 1, Day 2 and Day 3

The hot side temperature's pattern is similar to Figure 6 and Figure 7 due to the same reason. However, the cold side's temperature didn't vary that much (around $5^{\circ} \mathrm{C}$ ) because the heat transferred to the cold side and heat sink was dissipated effectively to the underground soil. The underground soil can be considered as a large heat absorbing reservoir. 


\section{CONCLUSION}

Based on the discussions and analysis, it can be concluded that the development of an electrical power generator by using TEG, focal lens and underground heat dissipation system has good potential for further studies and developments. Even though the amount of power produced by the system is quite low but reasonable due to the peltier type design (not suitable for high temperature), the cooling system can maintain almost a constant temperature without using any external power. Future development can replace the peltier type with the non pelteir type (known as TEG) to produce more electrical power.

\section{ACKNOWLEDGEMENTS}

I would like to thank Universiti Tenaga Nasional for funding this project under the UNITEN Internal Research Grant Application 2016 (UNIIG).

\section{REFERENCES}

[1] R. Ragaini and A. Zichichi, International Seminar on Nuclear War and Planetary Emergencies, 34th session. New Jersey: World Scientific, 2006

[2] B. Sørensen, Renewable energy. Burlington, MA: Academic Press, 2011.

[3] International Energy Agency, "Statistics on electrical information", 2015.

[4] M. Moghaddas, An experimental and theoretical analysis of a thermoelectric generator. 1986.

[5] Adroja, Mr Nikunj; B.Mehta, Prof Shruti; Shah, Mr Pratik, "Review of thermoelectricity to improve energy quality", 2015

[6] Gizmag.com, 'World's most efficient thermoelectric material developed', 2015. [Online]. Available: http://www.gizmag.com/most-efficient-thermoelectric-material/24210/. [Accessed: 02- Dec- 2015].

[7] A. Angeline A, J. J and L. Godson Asirvatham, "Performance Analysis of (Bi2Te3-PbTe) Hybrid Thermoelectric Generator", International Journal of Power Electronics and Drive Systems (IJPEDS), vol. 8, no. 2, p. 917, 2017.

[8] Seebeck, T. J., Thermoelectric generator. 1825.

[9] Stecanella, P.A.J.; Faria, M.A.A.; Domingues, E.G.; Gomes, P.H.G.; Calixto, W.P.; Alves, A.J., "Eletricity generation using thermoelectric generator - TEG," in Environment and Electrical Engineering (EEEIC), 2015 IEEE 15th International Conference on, pp. 2104-2108, 10-13 June 2015.

[10] Oetringer, K.; Kober, M.; Altstedde, M.K., "Upgrading hybrid-vehicles with a Thermoelectric Generator," in Ecological Vehicles and Renewable Energies (EVER), 2014 Ninth International Conference on, pp. 1-5, 25-27 March 2014.

[11] D. Baek et al., "Reconfigurable thermoelectric generators for vehicle radiators energy harvesting," 2017 IEEE/ACM International Symposium on Low Power Electronics and Design (ISLPED), Taipei, Taiwan, 2017, pp. 1-6.

[12] N. Baatar and S. Kim, "A Thermoelectric Generator Replacing Radiator for Internal Combustion Engine Vehicles", TELKOMNIKA (Telecommunication Computing Electronics and Control), vol. 9, no. 3, p. 523, 2011.

[13] Law Choon Chuan; Wahid, H.; Leow Pei Ling, "A charge pump-based power conditioning circuit for low powered thermoelectric generator (TEG)," in Control Conference (ASCC), 2015 10th Asian, pp.1-6, May 31 2015-June 3 2015.

[14] Niotaki, K.; Georgiadis, A.; Collado, A., "Thermal energy harvesting for power amplifiers," in Radio and Wireless Symposium (RWS), 2013 IEEE, pp.196-198, 20-23 Jan. 2013.

[15] Lineykin, S.; Ruchaevsky, I.; Kuperman, A., "Analysis and optimization of TEG-heatsink waste energy harvesting system for low temperature gradients," in Power Electronics and Applications (EPE'14-ECCE Europe), 2014 16th European Conference on, pp.1-10, 26-28 Aug. 2014.

[16] Y. Jeyashree, A. V. Juliet and A. A. Joseph, "Experimental analysis of thermoelectric generator using solar energy," 2014 International Conference on Smart Structures and Systems (ICSSS), Chennai, 2014, pp. 67-71.

[17] A. E. Özdemir, Y. Köysal, T. Atalay and E. Özbaş, "Conceptual design of solar and sea based renewable energy production with thermoelectric generator," 2015 9th International Conference on Electrical and Electronics Engineering (ELECO), Bursa, 2015, pp. 403-405.

[18] Feng Cao; Junjun Zhang; Hongfei Wu; Haibing Hu; Yan Xing; Xudong Ma, "A dual-input Boost-Buck converter with coupled inductors for TEG applications," in Energy Conversion Congress and Exposition (ECCE), 2013 IEEE, pp.2020-2025, 15-19 Sept. 2013.

[19] Jun, Huang; Peng, Xu; Hongfei, Wu; Yan, Xing, "A distributed MPPT control for a hybrid centralized-distributed TEG power generation system," in Industrial Electronics and Applications (ICIEA), 2015 IEEE 10th Conference on, pp.741-744, 15-17 June 2015.

[20] N. D. Trip, A. Şchiop and A. Burca, "Considerations on the use of a MPPT circuit for a thermoelectric generator," 2017 14th International Conference on Engineering of Modern Electric Systems (EMES), Oradea, 2017, pp. 252-255.

[21] V. Cermák, Underground temperature and inferred climatic temperature of the past millennium. [Ottawa]: [National Research Council], 1971.

[22] S. Samadinasab, F. Namdari and M. Bakhshipor, "The Influence of Moisture and Temperature on the Behavior of Soil Resistivity in Earthing Design Using Finite Element Method", Indonesian Journal of Electrical Engineering and Computer Science, vol. 2, no. 1, p. 11, 2016. 
[23] M. Nesarajah and G. Frey, "Thermoelectric power generation: Peltier element versus thermoelectric generator," IECON 2016 - 42nd Annual Conference of the IEEE Industrial Electronics Society, Florence, 2016, pp. 4252-4257.

\section{BIOGRAPHIES OF AUTHORS}

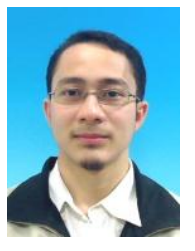

Syed Zainal Abidin Syed Kamarul Bahrin was born on January 22, 1984. He obtained his Bachelor of Electrical and Electronics Engineering (2006) and Master of Electrical Engineering (2012) at Universiti Tenaga Nasional, Malaysia. He is currently doing his PhD in Engineering that focuses on robotics at Universiti Tenaga Nasional, Malaysia. His topics of research include education, renewable energy, robotics, system automation, electrical machinery and automotive.

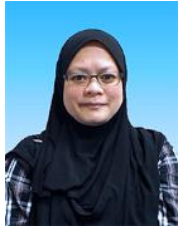

Sabarina Jaafar was born on March 16, 1978. She obtained her Bachelor of Electrical Power (Hons.) (2001) and Master in Electrical engineering (2009) at Universiti Tenaga Nasional, Malaysia. She is currently working as Lecturer in Electrical Power Department, at Universiti Tenaga Nasional, Malaysia. Her topics of research include education, renewable energy, electrical machinery, drives and power electronics. 